\title{
A Phytoplasma Belonging to a 16Srlll-A Subgroup and dsRNA Virus Associated with Cassava Frogskin Disease in Brazil
}

Adriana N. de Souza and Fábio N. da Silva, Department of Plant Pathology, UFV, Viçosa, Brazil; Ivan P. Bedendo, Department of Plant Pathology and Nematology, ESALQ/USP, Piracicaba, Brazil; and Claudine M. Carvalho, Department of Plant Pathology, UFV, Viçosa, Brazil

\begin{abstract}
de Souza, A. N., da Silva, F. N., Bedendo, I. P., and Carvalho, C. M. 2014. A phytoplasma belonging to a 16SrIII-A subgroup and dsRNA virus associated with Cassava frogskin disease in Brazil. Plant Dis. 98:771-779.

Cassava frogskin disease (CFSD) is a particular threat in cassava because symptoms remain hidden until harvest and losses can be total. The information related to the etiological agent of this disease is contradictory, because some authors believe it is caused by phytoplasmas while others believe that it is caused by a virus. In order to refine detection protocols and to characterize organisms associated with CFSD in Brazil, 32 symptomatic and 20 asymptomatic cassava plants were collected in Minas Gerais state. Total DNA was extracted and used for nested polymerase chain reaction (PCR) to detect phytoplasmas. Because endophytic Bacillus spp. led to false positives, primers were designed to facilitate the detection of phytoplasma in the presence of

bacteria. In addition, double-stranded (ds)RNA was extracted from tubers and used in reverse-transcription PCR for the detection of the RNA-dependent RNA polymerase gene from Cassava frogskin virus segment 4 . The detected phytoplasma was identified as belonging to the group 16SrIII-A by restriction fragment length polymorphism (RFLP), sequencing, and RFLP in silico. This is the first report of a phytoplasma belonging to the 16SrIII-A group associated with cassava plants, the first molecular characterization of a phytoplasma associated with CFSD in Brazil, and a first report of phytoplasma and a dsRNA virus (possible reovirus) co-infecting cassava plants with CFSD symptoms.
\end{abstract}

Cassava (Manihot esculenta Crantz; Euphorbiaceae) is one of the main food staples in developing countries and is of great socioeconomic importance, in particular to resource-poor farmers and in areas subject to drought. Brazil is the third-largest producer of cassava in the world and the crop is grown all over Brazil (12). Diseases, including those caused by viruses and phytoplasmas, are major limiting factors for production in Brazil (35). In Brazil, the first identification of phytoplasma as a disease-causing agent in cassava occurred in 1944 in the city of Lins, São Paulo. That set of symptoms was named cassava witches'-broom disease (34). However, the etiology of cassava witches'-broom disease was only determined many years later (13). The disease has subsequently spread throughout Brazil, leading to significant crop losses. Because cassava stems are the source of planting material for the next cycle, control of disease spread has been difficult (13). Cassava frogskin disease (CFSD) was first discovered in Colombia in 1971 (15). It may cause major losses in cassava yield, mainly affecting tubers: deep lesions, reduced diameter, and increased woodiness. Symptoms on the aerial parts of the plant are uncommon $(1,2)$. The etiology of CFSD needs to be elucidated. Alvarez et al. (1) detected a phytoplasma associated with CFSD; it was identified by nested polymerase chain reaction (PCR) and restriction fragment length polymorphism (RFLP) as belonging to the phytoplasma ribosomal group $16 \mathrm{SrIII}$ and ribosomal protein group rpIII-H (2). However, Calvert et al. (5) detected a double-stranded (ds)RNA virus in the phloem of cassava plants with CFSD through visualization of isometric viral particles by electron microscopy and comparison of fragments corresponding to the RNA-dependent RNA polymerase (RdRp) gene with other reoviruses (5). The results presented by Calvert et al. (5) suggest that a virus probably belonging to the Reoviridae family is associated with CFSD. However, each of

Corresponding author: C. M. Carvalho, E-mail: claudine.carvalho@ufv.br

Accepted for publication 25 November 2013.

http://dx.doi.org/10.1094/PDIS-04-13-0440-RE

(C) 2014 The American Phytopathological Society these two studies was directed at the detection of a single pathogen, with no investigation of the possibility of simultaneous occurrence of both pathogens.

Phytoplasmas are small pathogenic prokaryotes without cell wall, surrounded by a single membrane and having pleomorphic cells (9). They possess a single circular or linear chromosome and may additionally contain up to four different plasmids. The chromosome has reduced size compared with the ancestral gram-positive bacteria $(3,6,21,28,38)$. They are restricted to the phloem of their host plants and multiply inside the insect vectors (15). Recently, its cultivation in axenic culture has become possible (7), although details about the medium are not available. The most common symptoms seen in diseases caused by phytoplasmas are (i) phyllodes, (ii) witches'-broom, (iii) virescence, (iv) dwarfism, (v) sterility of floral organs, (vi) wrinkled leaves, and (vii) yellowing (4). The distribution and accumulation of phytoplasmas in host plants can be quite variable (33). A low concentration of microorganisms in certain tissues, as well as the presence of inhibitors in the host tissue, may render their detection difficult (18). An additional problem related to the detection of phytoplasmas is the presence of Bacillus spp. on the plant surface or endophytically, because certain genera of bacteria have a high nucleotide sequence homology with the $16 \mathrm{~S}$ ribosomal (r)DNA phytoplasma (25). The presence of these bacteria can interfere in the amplification reactions, leading to false positives and making it difficult to detect the pathogen (16). Moreover, the presence of different operons in the 16 rRNA gene may hamper its characterization (24), which is based on the comparison of the restriction patterns of $16 \mathrm{~S}$ rDNA fragments using different restriction enzymes (22).

Viruses belonging to the Reoviridae family have icosahedral particles ranging between 60 and $80 \mathrm{~nm}$ in diameter. Their genome is composed of 9 to 12 segments of linear dsRNA, depending on the genus. Conserved proteins such as $\mathrm{RdRp}$ and capsid proteins are used to distinguish members of different genera. Members of the family Reoviridae that infect plants can replicate in both plants and leafhoppers (19).

Despite the presence of cassava plants showing characteristic symptoms of the CFSD in Brazil, little is known about the presence of a phytoplasma or a virus associated with these symptoms 
in cassava. In the present article, cassava plants with symptoms of CFSD collected in Minas Gerais, Brazil, were analyzed for the presence or absence of virus and phytoplasma in order to make the diagnosis of this disease more accurate. Primers were designed to allow the detection of phytoplasma in cassava in the presence of endophytic bacteria. Additionally, the molecular characterization of the phytoplasma was performed through amplification of $16 \mathrm{~S}$ rDNA, followed by RFLP analysis, nucleotide sequencing, and phylogenetic analysis. The presence of a dsRNA virus was confirmed through reverse transcription PCR, cloning, and sequencing. The analyses showed that plants with symptoms of CFSD had both a phytoplasma, characterized as belonging to 16SrIII-A group, and a virus from the Reoviridae family. This is the first report of a phytoplasma belonging to $16 \mathrm{SrIII}-\mathrm{A}$ group in cassava plants, the first reported case of a virus associated with CFSD in Brazil, and also the first reported case of the joint presence of a phytoplasma and a virus associated with CFSD.

\section{Materials and Methods}

Sources of symptomatic and asymptomatic cassava. Fifty-two cassava plants were collected from a single field in Mocambinho (Jaíba, Minas Gerais, Brazil), where CFSD is prevalent. Of these plants, 32 had obvious symptoms of the disease while 20 were asymptomatic. Samples were collected from tubers, stems, and leaves of each plant for analysis. A healthy cassava plant was collected from Viçosa, Minas Gerais, where CFSD has never been reported, for use as a negative control in the detection of phytoplasmas and viruses.

DNA extraction. Total DNA was extracted from all cassava samples (tubers, stems, and leaves) following the protocol of Doyle and Doyle (10), with some modifications. Approximately $100 \mathrm{mg}$ of plant tissue, mainly from midribs and phloem regions, was macerated in liquid nitrogen and then transferred to $1.5-\mathrm{ml}$ microtubes. To each microtube, $800 \mu \mathrm{l}$ of $2 \times$ cetyltrimethylammonium bromide extraction buffer and $0.2 \% \beta$-mercaptoethanol, preheated to $60^{\circ} \mathrm{C}$, were added. The microtubes were vortexed and incubated at $65^{\circ} \mathrm{C}$ for $60 \mathrm{~min}$, inverted every $10 \mathrm{~min}$ in order to homogenize the suspension. After incubation, $600 \mu \mathrm{l}$ of chloroform/isoamyl alcohol (24:1) was added to each microtube. The solution was homogenized by inverting the tubes and they were centrifuged for $10 \mathrm{~min}$ at $14,000 \mathrm{rpm}$. The upper (aqueous) phase was transferred to a new microtube (approximately $540 \mu \mathrm{l}$ ). To these new microtubes, $540 \mu \mathrm{l}$ of cold isopropanol was added. The microtubes were left overnight at $-20^{\circ} \mathrm{C}$ for greater precipitation of nucleic acids. After incubation, the microtubes were centrifuged at $14,000 \mathrm{rpm}$ for $10 \mathrm{~min}$. The supernatant was discarded and the pellet formed was washed twice with $1 \mathrm{ml}$ of $80 \%$ ethanol. The pellet was resuspended in 500 $\mu \mathrm{l}$ of $1 \mathrm{M} \mathrm{NaCl}$. The microtubes were incubated for $60 \mathrm{~min}$ at $4^{\circ} \mathrm{C}$ and centrifuged at $14,000 \mathrm{rpm}$ for $10 \mathrm{~min}$. The pellet formed was washed twice with $1 \mathrm{ml}$ of $80 \%$ ethanol. After evaporation of all the ethanol, the pellet was resuspended in $60 \mu \mathrm{l}$ of TE plus RNase. The microtubes were stored at $-20^{\circ} \mathrm{C}$ for later use.

Phytoplasma detection. We performed a nested PCR using universal primers for phytoplasma detection, P1 and P7, followed by the amplification with primers FTP (F) and FTP (R), developed in this study to make possible the detection in the presence of endophytic bacteria (Table 1) $(8,23,32)$. These primers amplified an 816-bp fragment from the $16 \mathrm{~S}$ rDNA of this phytoplasma, without

Table 1. Primers used in polymerase chain reactions

\begin{tabular}{|c|c|c|}
\hline Primers & Nucleotide sequence & Reference \\
\hline P1 & $5^{\prime}$ AAG AGT TTG ATC CTG GCT CAG GAT T $3^{\prime}$ & 8 \\
\hline P7 & 5' CGT CCT TCA TCG GCT CTT 3' & 32 \\
\hline $\mathrm{R} 16 \mathrm{~F} 2 \mathrm{n}$ & $5^{\prime}$ GAA ACG ACT GCT AAG ACT GG $3^{\prime}$ & 23 \\
\hline R16R2 & $5^{\prime}$ TGA CGG GCG GTG TGT ACA AAC CCC G 3' & 23 \\
\hline FTP(F) & $5^{\prime}$ AAG GTA TAC TTA AGG AGG $3^{\prime}$ & This study \\
\hline FTP(R) & $5^{\prime}$ TTT CCT GAT AAC CTC CA $3^{\prime}$ & This study \\
\hline F110 & $5^{\prime}$ TGG CCG GGA GAA CAA TAA TA $3^{\prime}$ & 5 \\
\hline R1067 & 5' GCG AAG TAA GTT CCG TCG TT 3' & 5 \\
\hline
\end{tabular}

unspecific amplifications (see Results). The program used for the amplification with primers $\mathrm{P} 1 / \mathrm{P} 7$ had 30 cycles of $1 \mathrm{~min}$ at $94^{\circ} \mathrm{C}, 1$ min at $56^{\circ} \mathrm{C}$, and $2 \mathrm{~min}$ at $72^{\circ} \mathrm{C}$; for the primers $\mathrm{FTP}(\mathrm{F}) /(\mathrm{R})$, the program had 35 cycles of $1 \mathrm{~min}$ at $94^{\circ} \mathrm{C}, 1 \mathrm{~min}$ at $46^{\circ} \mathrm{C}$, and $1 \mathrm{~min}$ at $72^{\circ} \mathrm{C}$. Both programs had a single initial step of $1 \mathrm{~min}$ at $94^{\circ} \mathrm{C}$ and a final step of $7 \mathrm{~min}$ at $72^{\circ} \mathrm{C}$. The amplified product in the first reaction $(\mathrm{P} 1 / \mathrm{P} 7)$ was used as template for the second PCR at a dilution of 1:15 in Milli-Q water, using the primers $\operatorname{FTP}(\mathrm{F})$ and FTP(R).

Two cassava plants with symptoms of CFSD were kept in the greenhouse (samples 31 and 32) and used to amplify a 1,200-bp 16S rDNA fragment used for the taxonomical classification. A nested PCR was performed using the primers P1/P7, followed by $\mathrm{R} 16 \mathrm{~F} 2 \mathrm{n} / \mathrm{R} 2$ (Table 1), in order to obtain these sequences. The first reaction product $(1 \mu \mathrm{l})$ was used as a template for the second reaction. The program used for the primers $\mathrm{R} 16 \mathrm{~F} 2 \mathrm{n} / \mathrm{R} 2$ had 35 cycles of $1 \mathrm{~min}$ at $94^{\circ} \mathrm{C}, 2 \mathrm{~min}$ at $50^{\circ} \mathrm{C}$, and $3 \mathrm{~min}$ at $72^{\circ} \mathrm{C}$, with only one initial step of $1 \mathrm{~min}$ at $94^{\circ} \mathrm{C}$ and a final step of $7 \mathrm{~min}$ at $72^{\circ} \mathrm{C}$.

PCRs for phytoplasma detection were performed using the DNA amplification kit GoTaq Master Mix (Promega Corp.) according to the manufacturer's instructions. PCRs for sequencing were performed using the Platinum Taq DNA Polymerase High Fidelity (Invitrogen) according to the manufacturer's instructions. The final product amplified in the PCRs was subjected to agarose gel electrophoresis and, subsequently, the gels were stained with ethidium bromide and photographed under ultraviolet light.

dsRNA extraction and cDNA synthesis. dsRNA was extracted from the phloem region of all cassava tubers, using the viral dsRNA extraction kit (iNTRON Biotechnology). according to the manufacturer's instructions. For the cDNA synthesis, we used a primer R1067 complementary to the $3^{\prime}$ end of the coding strand (Table 1), $250 \mathrm{ng}$ of dsRNA, and $200 \mathrm{U}$ of SuperScript III RT (Invitrogen), according to the manufacturer's instructions, with a modification in the denaturation temperature $\left(98^{\circ} \mathrm{C}\right)$.

Viral detection. For the viral detection, we performed PCR using the primers F110 and R1067 (Table 1), which amplifies a fragment of approximately $950 \mathrm{bp}$, corresponding to the partial RdRp gene sequence of a possible reovirus. The program used for these primers had 35 cycles of $1 \mathrm{~min}$ at $94^{\circ} \mathrm{C}, 1 \mathrm{~min}$ at $50^{\circ} \mathrm{C}$, and 1.5 min at $72^{\circ} \mathrm{C}$. After 35 cycles, a single step of $72^{\circ} \mathrm{C}$ for $10 \mathrm{~min}$ was added for a final extension. The PCRs were performed using the Platinum Taq DNA Polymerase High Fidelity (Invitrogen), according to the manufacturer's instructions. The final product amplified in the PCRs was subjected to agarose gel electrophoresis, and the gels were stained with ethidium bromide and photographed under ultraviolet light.

Cloning and sequencing of fragments. For cloning, the fragments generated by PCR were purified using Illustra GFX PCR DNA and Gel Band Purification Kit (GE Healthcare), according to manufacturer's recommendations. The purified fragments were ligated into the pGEM T Easy Vector System I (Promega Corp.) and transformed to Escherichia coli DH5 $\alpha$ competent cells (31). After cloning, the plasmidial DNA was extracted from the E. colitransformed cells using the Illustra Kit Plasmidprep Mini Spin Kit (GE Healthcare), according to manufacturer's recommendations. The cloned fragments were sent for sequencing at Macrogen Inc.

RFLP in silico analysis. A restriction analysis in silico of the 1,200-bp sequences obtained by amplification of a $16 \mathrm{~S}$ rDNA using the primers $\mathrm{R} 16 \mathrm{~F} 2 \mathrm{n} / \mathrm{R} 2$ was performed using the online tool iPhyClassifier (39). The in silico restriction was made with the 17 commonly used restriction enzymes for RFLP analysis of phytoplasmas. The enzymes were AluI, BamHI, BfaI, Bsh1236 (BstUI), DraI, EcoRI, HaeIII, HhaI, HinfI, HpaI, HpaII, KpnI, MboI, MseI, $R s a \mathrm{I}, S s p \mathrm{I}$, and TaqI. A comparison of restriction patterns of the sequences obtained with the patterns described in literature was made in order to identify the group to which this phytoplasma belongs. We calculated the coefficients of similarity $(F)$ for each pair of isolates used for the analysis, through the iPhyClassifier (39), following the formula $F=2 N x y /(N x+N y)$, where $2 N x y$ is the number of bands in common in the profile between the two isolates 
and $N x$ and $N y$ are the numbers of bands existing in the profile of each isolate.

Phylogenetic analysis of $16 \mathrm{~S}$ rDNA and RdRp partial sequences. The two 1,200-bp 16S rDNA nucleotide sequences generated were aligned and compared with other sequences of 65 phy- toplasmas representative of different groups and subgroups within the group 16SrIII, including sequences of the phytoplasmas responsible for cassava witches'-broom disease (CaWB Br1 and CaWB Br2) and CFSD (CFSD1, -2, and -3) (Table 2). The nucleotide sequence of Acholeplasma palmae was used as an outgroup

Table 2. List of phytoplasmas used for phylogenetic analysis, with the classification and GenBank accession number (http://www.ncbi.nlm.nih.gov)

\begin{tabular}{|c|c|c|}
\hline Phytoplasma & Group/subgroup & Access number \\
\hline CaWB Br01 & 16SrIII-B & GU193976 \\
\hline CaWB Br02 & 16SrIII-B & GU193977 \\
\hline CFSD3 & 16SrIII-L & EU346761 \\
\hline CFSD2 & 16SrIII-L & AY737646 \\
\hline CFSD1 & 16SrIII-L & AY737647 \\
\hline CFSD Br1 & 16SrIII-A & $\ldots$ \\
\hline CFSD Br2 & 16SrIII-A & KF667079KF667080NC_007716 \\
\hline 'Candidatus Phytoplasma asteris' & $16 \mathrm{SrI}$ & 16 \\
\hline 'Ca. Phytoplasma aurantifolia' & 16SrII & U15442 \\
\hline 'Ca. Phytoplasma australasiae' & 16SrII & L33765 \\
\hline 16SrIII_A & 16SrIII-A & L33733 \\
\hline 16SrIII_B & 16SrIII-B & AF189288 \\
\hline 16SrIII_C & 16SrIII-C & FJ376626 \\
\hline 16SrIII_D & 16SrIII-D & FJ376627 \\
\hline 16SrIII_F & 16SrIII-F & AF510724 \\
\hline 16SrIII_G & 16 SrIII-G & AF190226 \\
\hline 16SrIII_J & 16SrIII-J & AF147706 \\
\hline 16SrIII_K & 16 SrIII-K & AF274876 \\
\hline 16SrIII_L & 16SrIII-L & EU169138 \\
\hline 16SrIII_M & 16SrIII-M & FJ226074 \\
\hline 16SrIII_N & $16 \mathrm{SrIII}-\mathrm{N}$ & FJ376629 \\
\hline 16SrIII_O & 16 SrIII-O & AF370120 \\
\hline 16SrIII_P & 16SrIII-P & AF370119 \\
\hline 16SrIII_Q & 16SrIII-Q & AF302841 \\
\hline 16SrIII_R & 16SrIII-R & AF373105 \\
\hline 16SrIII_S & 16SrIII-S & L04682 \\
\hline 16SrIII_T & 16SrIII-T & FJ231728 \\
\hline 16SrIII_U & 16SrIII-U & HM589213 \\
\hline 'Ca. Phytoplasma palmae' & 16SrIV & AF498307 \\
\hline 'Ca. Phytoplasma cocostanzaniae' & 16 SrIV & X80117 \\
\hline ‘Ca. Phytoplasma ulmi’ & $16 \mathrm{SrV}$ & AY197655 \\
\hline ‘Ca. Phytoplasma ziziphi' & $16 \mathrm{SrV}$ & AY197650 \\
\hline ‘Ca. Phytoplasma vitis' & $16 \mathrm{SrV}$ & AB052876 \\
\hline 'Ca. Phytoplasma rubi' & $16 \mathrm{SrV}$ & AY197642 \\
\hline 'Ca. Phytoplasma trifolii' & 16SrVI & AY390261 \\
\hline ‘Ca. Phytoplasma sudamericanum’ & $16 \mathrm{SrVI}$ & GU292081 \\
\hline ‘Ca. Phytoplasma fraxini’ & 16SrVII & AF092209 \\
\hline Loofah witches'-broom & 16SrVIII & AF353090 \\
\hline 'Ca. Phytoplasma phoenicium' & 16 SrIX & AF515636 \\
\hline ‘Ca. Phytoplasma prunorum’ & $16 \mathrm{SrX}$ & AJ542544 \\
\hline ‘Ca. Phytoplasma pyri’ & $16 \mathrm{SrX}$ & AJ542543 \\
\hline 'Ca. Phytoplasma mali' & $16 \mathrm{SrX}$ & AJ542541 \\
\hline ‘Ca. Phytoplasma spartii' & $16 \mathrm{SrX}$ & X92869 \\
\hline 'Ca. Phytoplasma oryzae’ & $16 \mathrm{SrXI}$ & AB052873 \\
\hline 'Ca. Phytoplasma fragariae' & 16SrXII & DQ086423 \\
\hline ‘Ca. Phytoplasma japonicum' & 16SrXII & AB010425 \\
\hline 'Ca. Phytoplasma australiense' & 16SrXII & L76865 \\
\hline 'Ca. Phytoplasma solani' & $16 \mathrm{SrXII}$ & AF248959 \\
\hline Mexican periwinkle virescence' & 16SrXIII & AF248960 \\
\hline 'Ca. Phytoplasma cynodontis' & 16SrXIV & AJ550984 \\
\hline 'Ca. Phytoplasma brasiliense' & $16 \mathrm{SrXV}$ & AF147708 \\
\hline ‘Ca. Phytoplasma graminis’ & 16SrXVI & AY725228 \\
\hline 'Ca. Phytoplasma caricae' & $16 \mathrm{SrXVII}$ & AY725234 \\
\hline ‘Ca. Phytoplasma americanum' & 16SrXVIII & DQ174122 \\
\hline ‘Ca. Phytoplasma castaneae' & 16SrXIX & AB054986 \\
\hline 'Ca. Phytoplasma rhamni’ & $16 \mathrm{SrXX}$ & X76431 \\
\hline ‘Ca. Phytoplasma pini’ & 16SrXXI & AJ632155 \\
\hline Nigerian coconut lethal decline & 16SrXXII & Y14175 \\
\hline Buckland valley grapevine yellows & 16SrXXIII & AY083605 \\
\hline Sorghum bunchy shoot & 16SrXXIV & AF509322 \\
\hline Weeping tea tree witches'-broom & $16 \mathrm{SrXXV}$ & AF521672 \\
\hline Mauritius sugarcane phytoplasma D3T1 & 16SrXXVI & AJ539179 \\
\hline Mauritius sugarcane D3T2 & 16SrXXVII & AJ539180 \\
\hline Havana Derbid & 16SrXXVIII & AY744945 \\
\hline 'Ca. Phytoplasma omanense' & 16SrXXIX & EF666051 \\
\hline ‘Ca. Phytoplasma tamaricis’ & $16 \mathrm{SrXXX}$ & FJ432664 \\
\hline 'Ca. Phytoplasma costaricanum' & 16SrXXXI & HQ225630 \\
\hline 'Ca. Phytoplasma malaysianum' & 16SrXXXII & EU371934 \\
\hline Acholeplasma palmae & $\ldots$ & L33734 \\
\hline
\end{tabular}


for analysis. Sequence alignment was performed using the program Muscle (11) implemented in the program Mega 5.5 (37). The phylogenetic analysis was performed using Bayesian inference (MB) through the program Mr. Bayes, based on the Monte Carlo Markov Chain (30). The model used was previously selected by Akaike Information Criterion through the program MrModeltest V.2 (Nylander, Upsala University). Ten million generations were used. Sampling of trees was carried out every 1,000 generations, generating 10,000 trees. In total, 2,500 trees (25\%) were excluded for the calculation of posterior probability and it was verified if there was convergence of cold chains. Trees were also constructed using neighbor-joining (NJ) and maximum likelihood (ML), using the program Mega 5.5 (data not shown). The trees were rooted using the sequence of Acholeplasma palmae as outgroup, because they belong to the same family of the genus 'Candidatus Phytoplasma' (Acholeplasmataceae).

The nucleotide sequence of RdRp obtained was aligned and a pairwise comparison was made with other sequence of the RdRp gene of Cassava frogskin virus, available in GenBank (DQ139870.1).

\section{Results}

Detection of phytoplasma in the samples collected. In total, 52 cassava plants, with and without symptoms of CFSD (Fig. 1), were collected and examined for the presence of phytoplasma in tubers, stems, and leaves, and it was possible to detect the phytoplasma in different tissues examined. Nested PCRs of all collected samples, using the primers $\mathrm{P} 1 / \mathrm{P} 7$ and $\mathrm{R} 16 \mathrm{~F} 2 \mathrm{n} / \mathrm{R} 2$, generated fragments of $1,200 \mathrm{bp}$, as expected for phytoplasmas. However, the sequencing results showed that the fragments belonged to different Bacillus spp. (endophytic in cassava), particularly Bacillus megaterium. Due to the high sequence homology among phytoplasmas and Bacillus spp. found on plant surfaces or endophytically, the detection of phytoplasma in the collected samples with universal primers commonly used for diagnosis (R16F2n/R2) was not possible. In order to overcome this problem, new primers were designed by comparing the sequences of the phytoplasma associated with CFSD present in the database and sequences of $B$. megaterium obtained from the amplification of cassava samples (Fig. 2). The new primers amplified a fragment of 816 bp (Fig. 3). They were named FTP(F) and FTP(R) and were used for the detection of phytoplasma in all cassava samples collected. Two of these fragments were cloned and then sequenced in order to confirm that the amplified fragment belonged to the phytoplasma.

Nested PCRs using primers P1/P7 in the first reaction and primers $\mathrm{FTP}(\mathrm{F}) /(\mathrm{R})$ in the second reaction gave consistent results. In all, 100 and $50 \%$ of symptomatic and asymptomatic plants, respectively, were positive for the presence of phytoplasmas. In the group of symptomatic plants, $21.9 \%$ of tuber samples, $68.8 \%$ of stem samples, and $87.5 \%$ of leaf samples were positive. In the group of asymptomatic plants, none of the tuber samples, $45 \%$ of stem samples, and $30 \%$ of the leaf samples was positive (Tables 3 and 4).

Viral detection in samples. All 52 samples were used for a dsRNA virus detection. A virus, probably from the Reoviridae family, was also detected in some of symptomatic and asymptomatic tubers, as previously demonstrated by Calvert et al. (5). In all, 50 and $20 \%$ of symptomatic and asymptomatic plants, respectively, were positive for the presence of virus in tubers (Tables 3 and 4). A fragment with expected size (isolate CFSV_Br1, accession number KF667081) and three nonexpected size fragments (i.e., nonspecific amplification) were cloned, sequenced, and analyzed. The nucleotide sequences of a fragment with expected size had $98.7 \%$ identity with the RdRp of Cassava frogskin virus segment 4 (DQ139870.1). Nonspecific amplification products were cloned and sequenced, and their sequences were found to correspond to mitochondrial sequences.
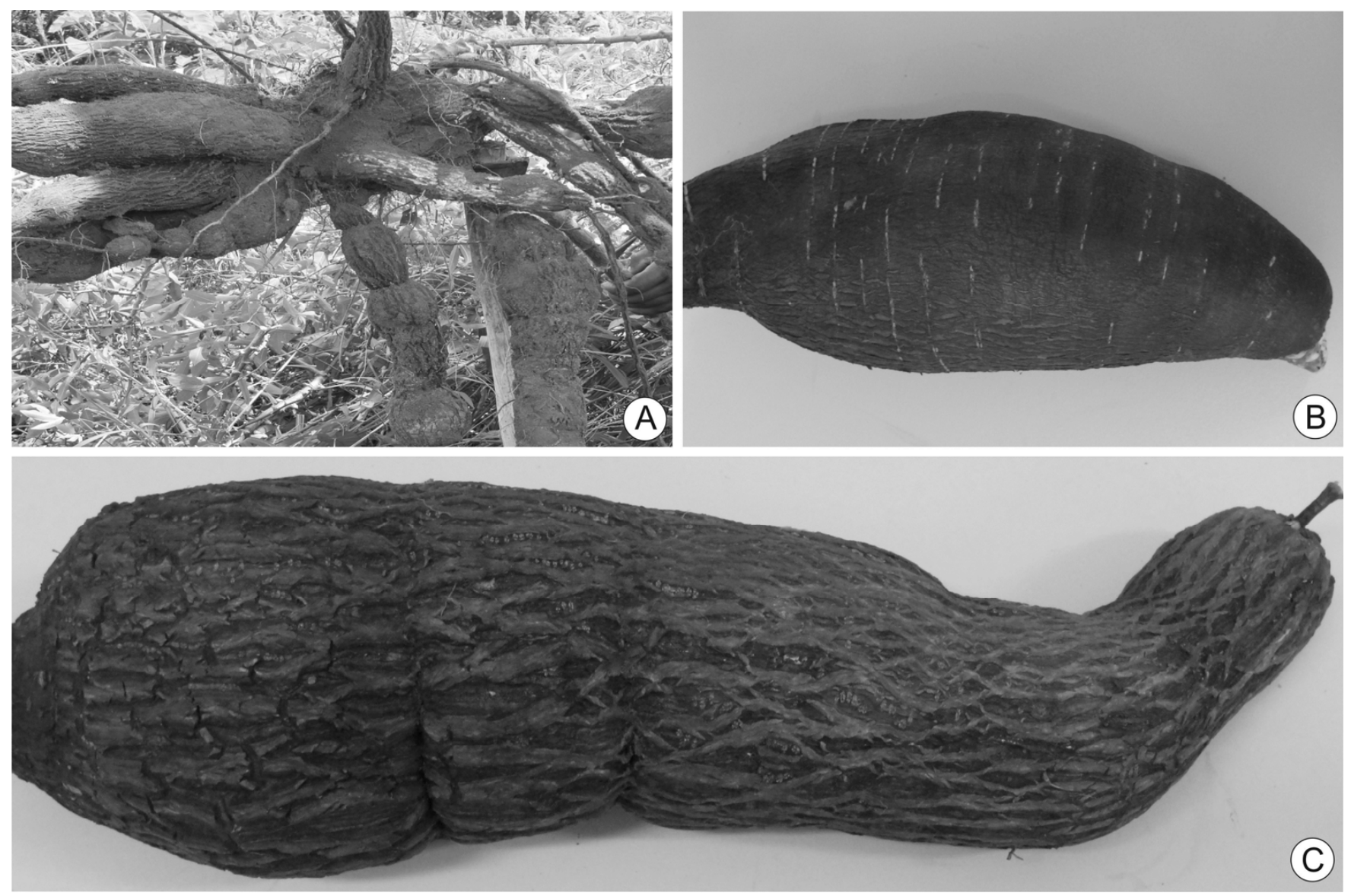

Fig. 1. Typical symptoms observed in cassava plants with cassava frogskin disease. A and C, Cassava tubers with deformities, deep injuries, looking woody and with reduced diameters. B, Tuber of healthy cassava plant, showing smooth surface and without deformations. 
Phytoplasma characterization by RFLP. Two symptomatic plants were kept in a greenhouse and were used to attempt amplification of a 1,200-bp fragment generated by primers R16F2n/R2. After several attempts, we amplified a 1,200-bp fragment from both plants. Cloning procedure was performed and eight clones were obtained, five from one plant and three from another plant. After sequencing, the 1,200-bp fragment was confirmed to be the phytoplasma infecting cassava plants (CFSD-Br1 and CFSD-Br2; Table 2). The clones obtained in each plant were aligned and a consensus sequence was obtained. These sequences were subjected to RFLP analysis in silico, with 17 enzymes commonly used for the characterization of phytoplasmas (Fig. 4), and were subsequently analyzed using the software iPhyClassifier (39). Additionally, enzymatic cleavage was performed using the enzymes BamHI, EcoRI, HaeIII, HinfI, MboI, RsaI, SspI, and TaqI to confirm the RFLP in silico. The same cleavage pattern from RFLP in silico was obtained with RFLP using endonucleases (data not shown). The $F$ value calculated comparing these two sequences and sequences of representative subgroups with group 16 SrIII showed higher values when compared with the representative of the 16SrIII-A subgroup (Fig. 5). The absence of only one cleavage site of the enzyme MseI in these clones, compared with the representative of 16SrIII-A subgroup, indicates that this phytoplasma is a variant of this subgroup (39).

Phylogenetic analysis of phytoplasmas. Phylogenetic analysis was performed with a total of 68 sequences, including at least one representative from each group, representatives of different subgroups of the 16SrIII group, three representatives of the phytoplasma associated with CFSD in Colombia (CFSD1, -2, and -3),

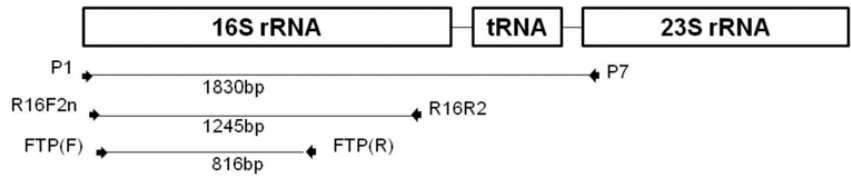

Fig. 3. Schematic representation of primer annealing region used for phytoplasma detection and size of fragments generated.

\begin{abstract}
BM2 AAAGATGGTTTCGGCTATCACTTACAGATGGGCCCGCGGTGCATTAGCTAGTTGGTGAGGTAACGGCTCACCAAGGCAACGATGCAT BM1 AAAGATGGTTTCGGCTATCACTTACAGATGGGCCCGCGGTGCATTAGCTAGTTGGTGAGGTAACGGCTCACCAAGGCAACGATGCAT CFSD AAGG---------TAT-ACTTAAGGAGGGGCTTGCGACACATTAGTTAGTTGGCAGGGTAAAGGCCTACCAAGACTATGATGTGT

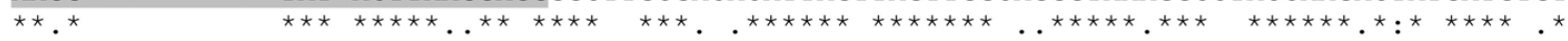

BM2 AgCCGACCTGAGAGGGTGATCGGCCACACTGGGACTGAGACACGGCCCAGACTCCTACGGGAGGCAGCAGTAGGGAATCTTCCGCAA BM1 AGCCGACCTGAGAGGGTGATCGGCCACACTGGGACTGAGACACGGCCCAGACTCCTACGGGAGGCAGCAGTAGGGAATCTTCCGCAA CFSD AGCTGGACTGAGAGGTTGAACAGCCACATTGGGACTGAGACACGGCCCAAACTCCTACGGGAGGCAGCAGTAGGGAATTTTCGGCAA

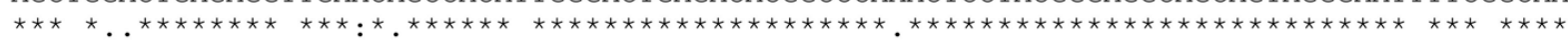

BM2 TGGACGAAAGTCTGACGGAGCAACGCCGCGTGAGTGATGAAGGCTTTCGGGTCGTAAAACTCTGTTGTTAGGGAAGAACAAGTACRA BM1 TGGACGAAAGTCTGACGGAGCAACGCCGCGTGAGTGATGAAGGCTTTCGGGTCGTAAAACTCTGTTGTTAGGGAAGAACAAGTACAA CFSD TGGAGGAAACTCTGACCGAGCAACGCCGCGTGAACGATGAAGTACCTCGGTATGTAAAGTTCTTTTATTAAGGAAGAAAAAAGAGTG

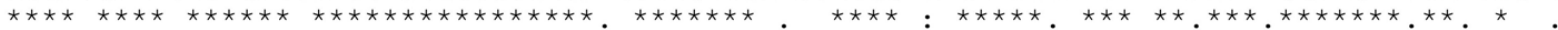

GAGTAACTGCTYGTACCTTGACGGTACCTAACCAGAAAGCCACGGCTAACTACGTGCCAGCAGCCGCGGTAATACGTAGGTGGCAAG GAGTAACTCTYGTACCTIGACGGTACCTAACCAGAAAGCCACGGCTAACTACGTGCCAGCAGCCGCGGTAATACGTAGGTGGCAAG CFSD GAAAAAC-----TCCCTTGACGGTACTTAATGAATAAGCCCCGGCTAATTATGTGCCAGCAGCCGCGGTAATACATAAGGGGCGAG

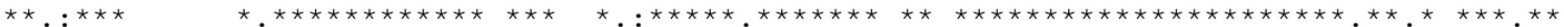

\begin{abstract}
BM2 CGTTATCCGGAATTATTGGGCGTAAAGCGCGCGCAGGCGGTTTCTTAAGTCTGATGTGAAAGCCCACGGCTCAACCGTGGAGGGTCA BM1 CGTTATCCGGAATTATTGGGCGTAAAGCGCGCGCAGGCGGTTTCTTAAGTCTGATGTGAAAGCCCACGGCTCAACCGTGGAGGGTCA CFSD CGTTATCCGGAATTATTGGGCGTAAAGGGTGCGTAGGCGGTTTAATAAGTCTATAGTTTAATTTCAGTGCTTAACGCTGTTGTGCTA

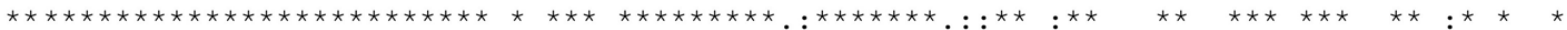

\begin{abstract}
BM2 TTGGAAACTGGGGAACTTGAGTGCAGAAGAGAAAAGCGGAATTCCACGTGTAGCGGTGAAATGCGTAGAGATGTGGAGGAACACCAG BM1 TTGGAAACTGGGGAACTTGAGTGCAGAAGAGAAAAGCGGAATTCCACGTGTAGCGGTGAAATGCGTAGAGATGTGGAGGAACACCAG CFSD - TAGAAACTGTTTACTAGAGTGAGTTAGAGGCAAGCGGAATTCCATGTGTAGCGGTAAAATGCGTAAATATATGGAGGAACACCAG

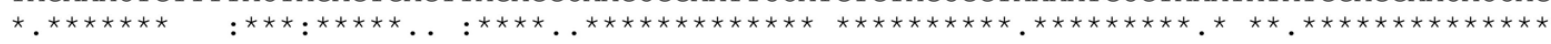

BM2 TGGCGAAGGCGGCTTTTTGGTCTGTAACTGACGCTGAGGCGCGAAAGCGTGGGGAGCAAACAGGATTAGATACCCTGGTAGTCCACG BM1 TGGCGAAGGCGGCTTTTTGGTCTGTAACTGACGCTGAGGCGCGAAAGCGTGGGGAGCAAACAGGATTAGATACCCTGGTAGTCCACG CFSD AGGCGTAGGCGGCTTGCTGGGACTTTACTGACGCTGAGGCACGAAAGCGTGGGGAGCAAACAGGATTAGATACCCTGGTAGTCCACA
\end{abstract}

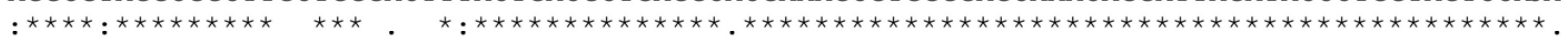

BM2 CCGTAAACGATGAGTGCTAAGTGTTAGAGGGTTTCCG- CCCTTTAGTGCTGCAGCTAACGCATTAAGCACTCCGCCTGGGGAGTACG BM1 CCGTAAACGATGAGTGCTAAGTGTTAGAGGGTTTCCG- CCCTTTAGTGCTGCAGCTAACGCATTAAGCACTCCGCCTGGGGAGTACG CFSD CCGTAAACGATGAGTACTAAGTG-TCGGGTAAAAC--------GGTACTGAAGTTAACACATTAAGTACTCCGCCTGAGTAGTACG

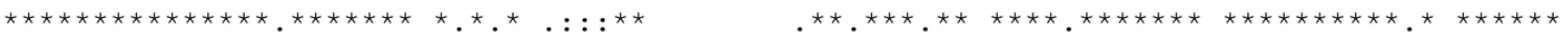

BM2 GTCGCAAGACTGAAACTCAAAGGAATTGACGGGGGCCCGCACAAGCGGTGGAGCATGTGGTTTAATTCGAAGCAACGCGAAGAACCT BM1 GTCGCAAGACTGAAACTCAAAGGAATTGACGGGGGCCCGCACAAGCGGTGGAGCATGTGGTTTAATTCGAAGCAACGCGAAGAACCT CFSD TACGCAAGTATGAAACTTAAAGGAATTGACGGGACTCCGCACAAGCGGTGGATCATGTTGTTTAATTCGAAGATACACGAAAAACT

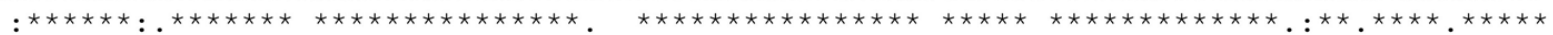

BM2 TACCAGGTCTTGACATCCTCTGAC--AACTCTAGAGATAGAGCGTTCCCCTTCGGGGGA

BM1 TACCAGGTCTTGACATCCTCTGAC--AACTCTAGAGATAGAGCGTTCCCCTTCGGGG-A

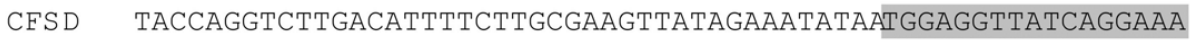

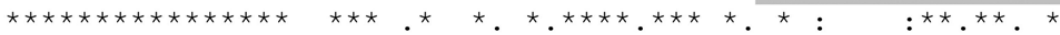

Fig. 2. Alignment of sequences of Bacillus megaterium (BM1 and BM2) with the sequence of the phytoplasma of cassava frogskin disease (CFSD) available in GenBank. Highlighted sequences correspond to primers FTP(F) and FTP(R), proposed and used in this study in order to detect phytoplasma causing CFSD in cassava. 
two representatives of the phytoplasma associated with cassava witches'-broom (CaWB1 and -2), the two clones obtained in this work, and a nucleotide sequence of $A$. palmae as the outgroup. The trees generated by different methods (NJ, ML, and MB) showed similar topology; therefore, only the MB tree is presented (Fig. 6).

Branches well supported by posterior probability values $(\geq 0.95)$ grouped all representatives of the 16SrIII group and the two clones obtained in this work, supporting the RFLP classification. It can be observed that the two clones obtained in this work were grouped with representative of the $16 \mathrm{SrIII}-\mathrm{L}$ and close to $16 \mathrm{SrIII}-\mathrm{A}$, 16 SrIII-G, and 16SrIII-S subgroups but are far from the representatives of CFSD from Colombia and from representatives of cassava witches'-broom disease.

\section{Discussion}

Many symptoms caused by phytoplasmas reflect changes in the plant's hormonal balance (36). With CFSD, symptoms in foliage are unusual and plants do not show typical symptoms of phytoplasma infections such as virescence, phyllody, wrinkling, dwarfism, sterility of flowers, or witches'-broom $(1,2)$. Woody-type tubers, with thick bark and reduced diameter, may be related to increased levels of lignin and suberin in tuber tissue, as previously reported in apple trees infected by phytoplasma (26).

It is quite common for contaminant microorganisms to interfere in the PCR in the process of detection of phytoplasmas (16). Due to this problem, additional care must be taken to avoid the occurrence of contamination, such as surface sterilization of plant tissues prior to DNA extraction and the use of filter tips, gloves, and contaminant-free water. The use of different combinations of primers described in the literature can be a solution if all the procedures listed above are insufficient. Another alternative consists of designing new primers based on existing nucleotide sequences, as carried out in this article.

The presence of phytoplasmas in the tissues of cassava plants has been proven here through nested PCR using different combinations of primers. The detection by nested PCR with the primers P1/P7 followed by $\operatorname{FTP}(\mathrm{F}) /(\mathrm{R})$ was quite efficient, with a positive result in $100 \%$ of the symptomatic plants and $50 \%$ of asymptomatic plants. It is noteworthy that even asymptomatic plants had a high incidence of phytoplasmas. Despite the presence of phytoplasmas, the absence of symptoms may be related to plant age at the moment of infection, as observed by Rapussi et al. (29) in cauliflower plants infected by a phytoplasma. If the phytoplasma is already present in the cassava stakes at planting, it will have enough time to accumulate in the tissues of the host, thus affecting the whole process of tuber formation. If infection occurs later in the growing cycle, the accumulation of the phytoplasma might not be enough to support the occurrence of visible symptoms, although still enough to allow detection.

Leaves and stems were the best tissues for detection. Detection of phytoplasma in the tubers was not very efficient. The presence

Table 4. Percentage of symptomatic, asymptomatic, and total plants infected with phytoplasma, virus, both, or neither

\begin{tabular}{lccc}
\hline Infected with & Symptomatic & Asymptomatic & Total plants \\
\hline Phytoplasma & 50 & 40 & 46.2 \\
Both & 50 & 10 & 3.8 \\
Virus & 0 & 10 & 34.6 \\
None & 0 & 40 & 15.4 \\
\hline
\end{tabular}

Table 3. Detection of phytoplasma and possible reovirus in different tissues of 32 symptomatic and 20 asymptomatic cassava plants collected in the city of Jaíba, Minas Gerais, Brazil ${ }^{\mathrm{a}}$

\begin{tabular}{|c|c|c|c|c|c|c|c|c|}
\hline \multirow[b]{3}{*}{ Sample } & \multicolumn{4}{|c|}{ Symptomatic plants } & \multicolumn{4}{|c|}{ Asymptomatic plants } \\
\hline & \multicolumn{3}{|c|}{ Phytoplasma } & \multirow{2}{*}{$\begin{array}{c}\text { Virus } \\
\text { Tuber } \\
\end{array}$} & \multicolumn{3}{|c|}{ Phytoplasma } & \multirow{2}{*}{$\begin{array}{c}\text { Virus } \\
\text { Tuber }\end{array}$} \\
\hline & Leaf & Stem & Tuber & & Leaf & Stem & Tuber & \\
\hline 1 & + & + & - & - & - & - & - & + \\
\hline 2 & + & + & - & + & + & - & - & - \\
\hline 3 & + & + & + & + & - & - & - & - \\
\hline 4 & + & + & - & + & - & - & - & - \\
\hline 5 & + & - & + & - & - & - & - & - \\
\hline 6 & + & - & - & + & + & + & - & - \\
\hline 7 & + & + & - & - & - & - & - & - \\
\hline 8 & + & + & - & + & - & - & - & - \\
\hline 9 & - & + & - & + & - & - & - & - \\
\hline 10 & + & + & - & + & - & - & - & - \\
\hline 11 & + & - & - & + & + & + & - & - \\
\hline 12 & + & - & - & - & - & + & - & + \\
\hline 13 & + & + & - & - & - & - & - & + \\
\hline 14 & + & - & - & + & - & + & - & - \\
\hline 15 & + & - & - & - & - & + & - & - \\
\hline 16 & + & - & - & + & - & + & - & + \\
\hline 17 & + & + & - & + & + & + & - & - \\
\hline 18 & - & + & - & + & - & - & - & - \\
\hline 19 & - & + & - & - & + & + & - & - \\
\hline 20 & + & + & - & - & + & + & - & - \\
\hline 21 & + & + & - & - & $\ldots$ & $\ldots$ & $\ldots$ & $\ldots$ \\
\hline 22 & + & + & + & - & $\ldots$ & $\ldots$ & $\ldots$ & $\ldots$ \\
\hline 23 & + & + & + & - & $\cdots$ & $\cdots$ & $\cdots$ & $\cdots$ \\
\hline 24 & + & - & - & + & $\ldots$ & $\ldots$ & $\ldots$ & $\ldots$ \\
\hline 25 & + & + & + & + & $\cdots$ & $\cdots$ & $\cdots$ & $\cdots$ \\
\hline 26 & + & - & - & - & $\ldots$ & $\ldots$ & $\ldots$ & $\ldots$ \\
\hline 27 & + & + & - & - & $\cdots$ & $\cdots$ & $\cdots$ & $\cdots$ \\
\hline 28 & + & - & - & - & $\ldots$ & $\ldots$ & $\ldots$ & $\ldots$ \\
\hline 29 & - & + & - & - & $\ldots$ & $\ldots$ & $\ldots$ & $\ldots$ \\
\hline 30 & + & + & - & - & $\cdots$ & $\cdots$ & $\cdots$ & $\cdots$ \\
\hline 31 & + & + & + & + & $\ldots$ & $\ldots$ & $\ldots$ & $\ldots$ \\
\hline 32 & + & + & + & + & $\ldots$ & $\ldots$ & $\ldots$ & $\ldots$ \\
\hline$\Sigma$ Positives & 28 & 22 & 7 & 16 & 6 & 9 & 0 & 4 \\
\hline Positives (\%) & 87.5 & 68.8 & 21.9 & 50 & 30 & 45 & 0 & 20 \\
\hline
\end{tabular}

a Presence (+) or absence (-) of specific polymerase chain reaction product. 
of PCR inhibitors may be one of the factors that explain the lower detection rate in the tuber tissues (14). To reduce the interference of these inhibitors in the PCR, a dilution of the DNA extract is recommended prior to the first reaction and between the two nested PCRs (17). Even with the implementation of these dilutions, the

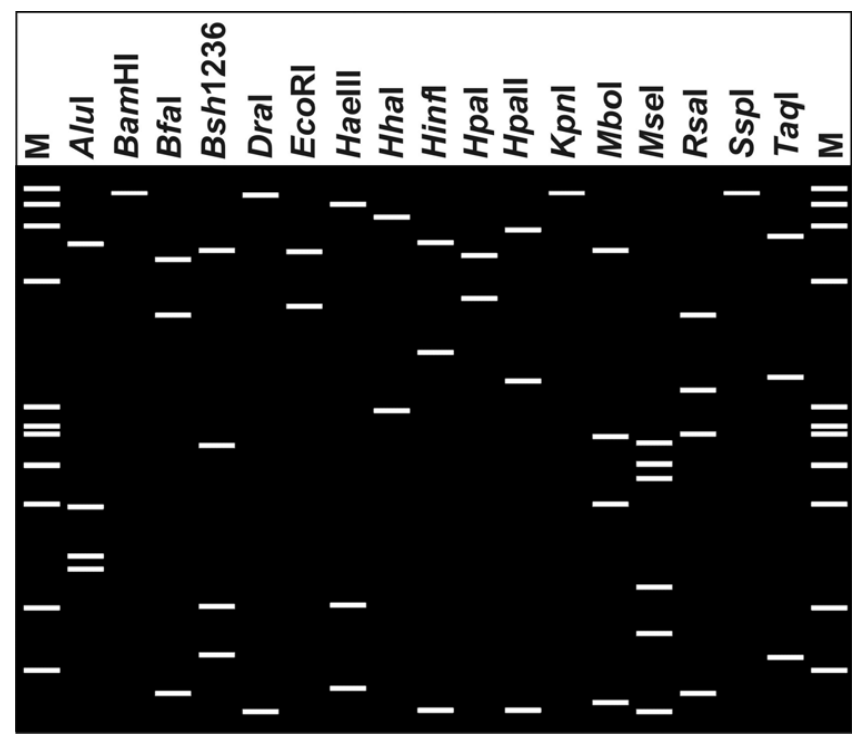

Fig. 4. Restriction fragment length polymorphism pattern in silico generated by the nucleotide sequences from the phytoplasmas (CFSD_Br1 and CFSD_Br2) obtained from cassava plants showing cassava frogskin disease (CFSD) symptoms. $\mathrm{M}=$ phiX174 digested with Haelll. detection rate in the tubers was still very low. Due to the fact that phytoplasmas are distributed and accumulated heterogeneously in plants, detection should be tried using samples extracted from different parts of the plant to ensure the reliability of the results.

The molecular characterization was performed by RFLP and RFLP in silico analyses in sequences generated by R16F2n/R2 primers. The first characterization of a phytoplasma associated with CFSD, in Colombia, suggested the inclusion of this phytoplasma in a new subgroup called 16SrIII-L (2). However, the restriction pattern generated by the sequence determined by $\mathrm{R} 16 \mathrm{~F} 2 \mathrm{n} / \mathrm{R} 2$ primers by RFLP in silico analysis shows no differences when compared with the restriction pattern of the 16SrIII-B subgroup phytoplasma, which contains the phytoplasmas associated with cassava witches'-broom disease (CaWB Br1 and CaWB $\mathrm{Br} 2$ ) (13). The sequences generated in this study were compared with the sequence of phytoplasma associated with CFSD described previously (2). Although these have the same MseI cleavage pattern, they differed in the cleavage pattern of the enzymes $M b o \mathrm{I}$ and HpaII. This excludes the possibility of belonging to the same subgroup. The RFLP and RFLP in silico analyses of fragments generated by $\mathrm{R} 16 \mathrm{~F} 2 \mathrm{n} / \mathrm{R} 2$ primers of the phytoplasma characterized in this work show that it belongs to a variant of 16SrIII-A subgroup. This is the first report of a phytoplasma belonging to the 16SrIII-A subgroup in cassava plants and also the first reported case and molecular characterization of the phytoplasma associated with CFSD in Brazil.

The characterization based on only a part of the sequence of the $16 \mathrm{~S}$ rDNA and the separation of phytoplasma subgroups is still very subjective, because it shows no relationship to biological characteristics of the pathogen, its host, or the type of symptoms caused. Differences of only a few nucleotides in these sequences

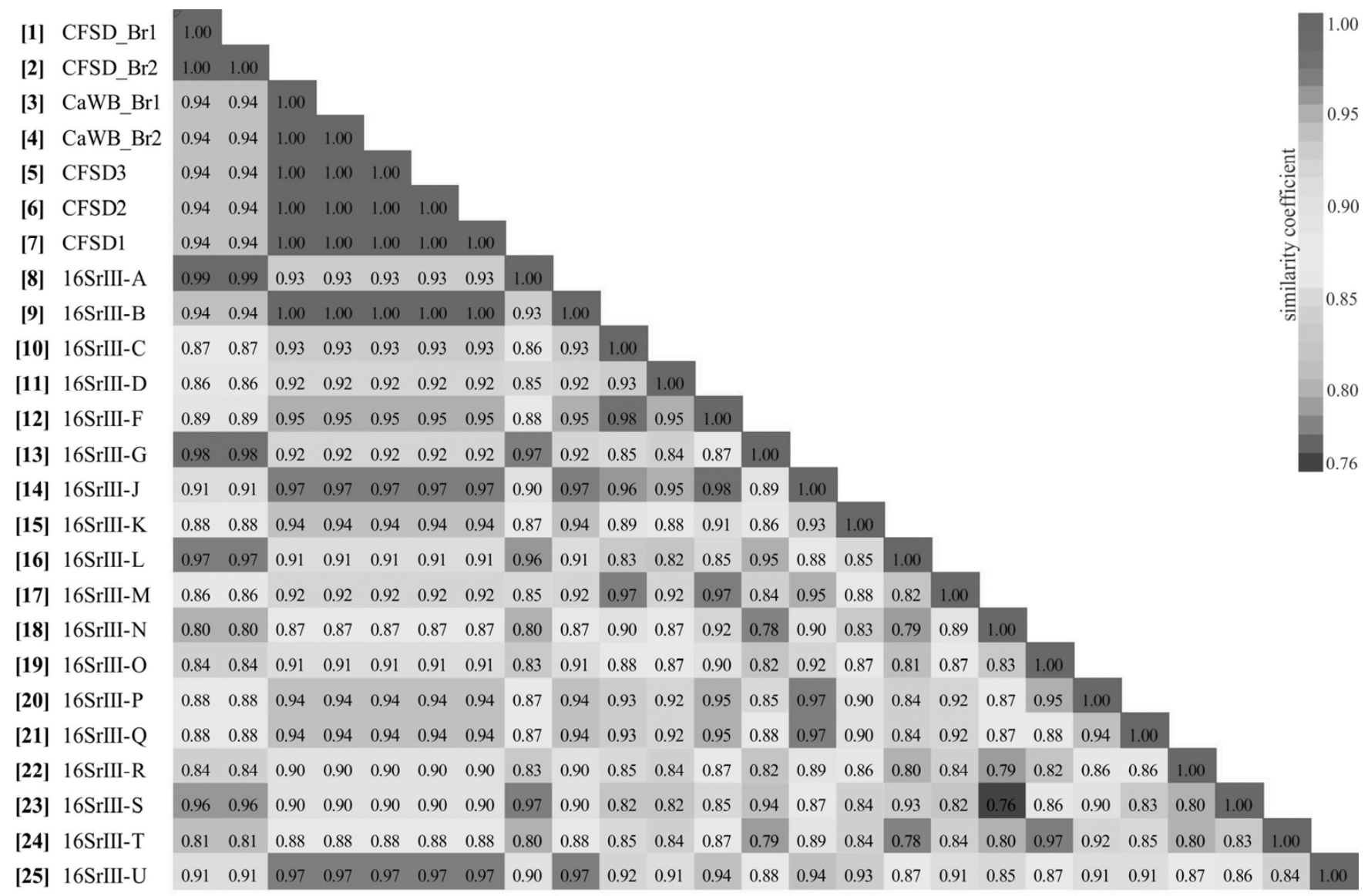

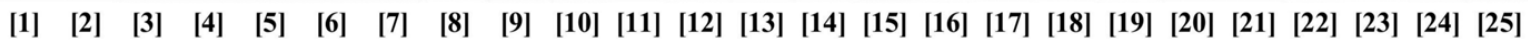

Fig. 5. Two-dimensional plot representing the similarity coefficient among 25 16Srll phytoplasmas, including two sequences obtained in this work (CFSD_Br1 and CFSD_Br2), three sequences of phytoplasma associated with cassava frogskin disease (CFSD) in Colombia, and two sequences of a phytoplasma associated with Cassava witches'-broom disease in Brazil (CaWB_Br1 and CaWB_Br2). 
do not seem to be able to solve problems in the separation of these phytoplasmas. One example is the phytoplasmas associated with cassava. The phytoplasmas responsible for cassava witches'-broom disease and the phytoplasma related to the CFSD in Colombia have the same restriction fragment pattern of $16 \mathrm{~S}$ rDNA and have cassava as a host in common but cause very different symptoms $(2,13)$. Although the phytoplasma characterized in this work and that which is associated CFSD in Colombia has the same host and the same type of symptoms, they have distinct cleavage patterns of $16 \mathrm{~S}$ rDNA and, thus, are characterized differently. The inability to cultivate these organisms makes their characterization difficult. Increased knowledge of the relationships with insect vectors, interaction with its hosts, and larger number of genes or genomes being sequenced of several phytoplasma groups will bring greater clarity and greater support for the classification of this group of plant pathogens.

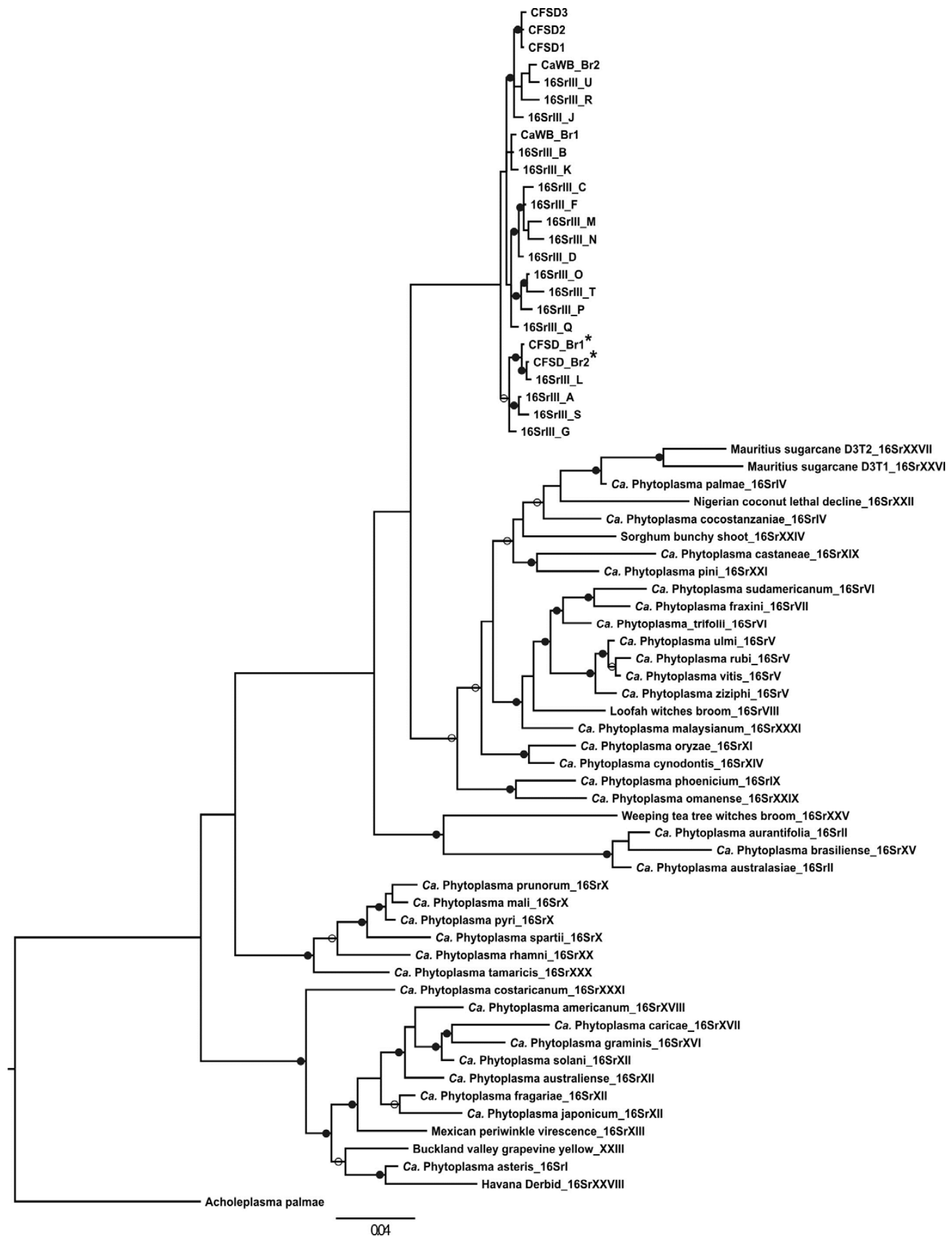

Fig. 6. Phylogenetic relationships between sequences of fragments from different groups of phytoplasmas and 16Srlll subgroups, amplified by primers R16F2n/R2, through Bayesian inference (implemented in MrBayes v.2, with model $G T R+1+G$ and 10 million generations). Acholeplasma palmae was used as outgroup. Support for the nodes is presented as filled circles (posterior probabilities from 0.95 to 1.0) or open circles (posterior probabilities from 0.85 to 0.94 ). CFSD1, CFSD2, and CFSD3 are sequences of phytoplasma associated with cassava frogskin disease (CFSD) in Colombia, classified as 16Srlll-L by the authors (2) and CaWB_Br1 and CaWB_Br2 are sequences of phytoplasma associated with Cassava witches'-broom disease in Brazil, classified as 16Srlll-B by the authors (13). Asterisks indicate 16 Srlll-A obtained in this work. 
A virus, probably belonging to the Reoviridae family, was also detected in some of symptomatic and asymptomatic tubers, as previously demonstrated by Calvert et al. (5). Symptomatic plants presented only phytoplasma or both phytoplasma and virus. Asymptomatic plants presented only phytoplasmas, only virus, or none or both pathogens (Tables 2 and 3). Interestingly, in most of the roots in which the virus was detected, it was not possible to detect phytoplasma. These results may suggest a possible spatial separation between the two organisms due, for example, to the preference of colonization by certain tissues or organs $(20,27)$. The results also suggest that the symptoms of CFSD are caused only by phytoplasmas, because of their presence in all symptomatic plants even without the presence of virus. However, a synergistic interaction may also be occurring, leading to an increase in disease severity in plants in which the virus is also present. Transmission tests should be performed to confirm the etiology of the disease.

In summary, the data obtained with this research prove the existence of a phytoplasma and a putative reovirus associated with cassava plants presenting the CFSD in the town of Jaíba, Minas Gerais, Brazil. This phytoplasma was characterized as belonging to the 16SrIII group and subgroup A, based on sequence of $16 \mathrm{~S}$ rDNA. This is the first report of a phytoplasma belonging to the 16SrIII-A subgroup associated with cassava plants and the first molecular characterization of a phytoplasma causing CFSD in Brazil. The virus found showed high similarity to a Reoviridae family. This is the first report of a virus associated with CFSD in Brazil, and also the first report of the presence of both phytoplasma and virus in cassava with CFSD symptoms.

\section{Acknowledgments}

We thank C. Lúcia Siqueira and G. Bispo de Oliveira (EMATER/MG) for their help in collecting cassava samples, CNPq for financial support, and $\mathrm{F}$. M. Zerbini Júnior for the use of his laboratory.

\section{Literature Cited}

1. Alvarez, E., Mejía, J. F., Llano, G. A., and Loke, J. B. 2007. Detection and characterization of a phytoplasma associated with frog skin disease in cassava. Bull. Insectol. 60:273-274.

2. Alvarez, E., Mejía, J. F., Llano, G. A., Loke, J. B., Calari, A., Duduk, B., and Bertaccini, A. 2009. Characterization of a phytoplasma associated with frogskin disease in cassava. Plant Dis. 93:1139-1145.

3. Bai, X., Zhang, J., Ewing, A., Miller, S. A., Radek, A. J., Shevchenko, D. V., Tsukerman, K., Walunas, T., Lapidus, A., Campbell, J. W., and Hogenhout, S. A. 2006. Living with genome instability: the adaptation of Phytoplasmas to diverse environments of their insect and plant hosts. J. Bacteriol. 188:3696.

4. Bertaccini, A., and Duduk, B. 2009. Phytoplasma and phytoplasma diseases: a review of recent research. Phytopathol. Mediterr. 48:355-378.

5. Calvert, L. A., Cuervo, M., Lozano, I., Villareal, N., and Arroyave, J. 2008. Identification of three strains of a virus associated with cassava plants affected by frogskin disease. J. Phytopathol. 156:647-653.

6. Chung, W. C., Chen, L. L., Lo, W. S., Lin, C. P., and Kuo, C. H. 2013. Comparative analysis of the Peanut Witches Broom Phytoplasma genome reveals horizontal transfer of potential mobile units and effectors. PLoS One 8:1-10.

7. Contaldo, N., Bertaccini, A., Paltrinieri, S., Windsor, H. M., and Windsor, G. D. 2012. Axenic culture of plant pathogenic phytoplasmas. Phytopathol. Mediterr. 51:607-617.

8. Deng, X., and Hiruki, C. 1991. Amplification of 16S rRNA genes from culturable and non-culturable Mollicutes. J. Microbiol. Methods 14:53-61.

9. Doi, Y. M., Teranaka, M., Yora, K., and Asuyama, H. 1967. Mycoplasma or PLT-group-like microorganisms found in the phloem elements of plants infected with mulberry dwarf, potato witches' broom, aster yellows, or paulownia witches' broom. Ann. Phytopathol. Soc. Jpn. 33:259-266.

10. Doyle, J. J., and Doyle, J. L. 1987. A rapid DNA isolation procedure from small quantities of fresh leaf tissues. Phytochem. Bull. 19:11-15.

11. Edgar, R. C. 2004. MUSCLE: multiple sequence alignment with high accuracy and high throughput. Nucleic Acids Res. 32:1792-1797.

12. FAO. 2012. Food and Agriculture Organization of the United Nations. http://faostat.fao.org

13. Flôres, D., Haas, I. C., Canale, M. C., and Bedendo, I. P. 2013. Molecular identification of a 16SrIII-B phytoplasma associated with cassava witches' broom disease. Eur. J. Plant Pathol. 137:237-242.

14. Galetto, L., and Marzachi, C. 2010. Real-time PCR diagnosis and quantification of phytoplasmas. Pages 1-18 in: Phytoplasmas: Genomes, Plant Hosts and Vectors. P. G. Weintraub and P. Jones, eds. CABI, Oxfordshire, UK

15. Hanboonsong, Y., Choosai, C., Panyim, S., and Damak, S. 2002. Transovarial transmission of sugarcane white leaf phytoplasma in the insect vector Matsumuratettix hiroglyphicus (Matsumura). Insect Mol. Biol. 11:97-103.

16. Harrison, N. A., Womack, M., and Carpio, M. L. 2002. Detection and characterization of a lethal yellowing (16SrIV) group phytoplasma in Canary Island date palms affected by lethal decline in Texas. Plant Dis. 86:676-681.

17. Heinrich, M., Botti, S., Caprara, L., Arthofer, W., Sttromer, S., Hanzer, V., Katinger, H., Bertaccini, A., and Machado, M. L. C. 2001. Improved detection methods for fruit tree phytoplasmas. Plant Mol. Biol. Rep. 19:169-179.

18. Hodgetts, J., and Dickinson, M. 2010. Phytoplasma phylogeny and detection based on genes other than 16S rRNA. Pages 93-113 in: Phytoplasmas: Genomes, Plant Hosts and Vectors. P. G. Weintraub and P. Jones, eds CABI, Oxfordshire, UK.

19. King, A. M. Q., Adams, M. J., Carstens, E. B., and Lefkowitz, E. J., eds. 2012. Virus Taxonomy. Classification and Nomenclature of Viruses. Ninth Report of the International Committee on Taxonomy of Viruses. Elsevier Academic Press, London.

20. Kogovsek, P., Kladnik, A., Mlakar, J., Znidaric, M. T., Dermastia, M., Ravnikar, M., and Pompe-Novak, M. 2011. Distribution of Potato virus $Y$ in potato plant organs, tissues, and cells. Phytopathology 101:1292-1300.

21. Kube, M., Schneider, B., Kuhl, H., Dandekar, T., Heitmann, K., Migdoll, A M., Reinhardt, R., and Seemuller, E. 2008. The linear chromosome of the plant-pathogenic mycoplasma 'Candidatus Phytoplasma mali'. BMC Genomics 9:306.

22. Lee, I. M., Gundersen-Rindal, D. E., Davis, R. E., and Bartoszyk, I. M. 1998. Revised classification scheme of phytoplasmas based on RFLP analyses of 16S rRNA and ribossomal protein gene sequence. Int. J. Syst. Bacteriol. 48:1153-1169.

23. Lee, I. M., Gundersen-Rindal, D. E., Hammond, R. W., and Davis, R. E. 1994. Use of micoplasmalike organisms (MLO) group-specific oligonucleotide primers for nested PCR assay to detect mixed MLO infections in a single host plant. Phytopathology 84:559-566.

24. Liefting, L. W., Andersen, M. T., Beever, R. E., Gardner, R. C., and Forster, R. L. 1996. Sequence heterogeneity in the two 16S rRNA genes of Phormium yellow leaf phytoplasma. Appl. Environ. Microbiol. 62:3133-3139.

25. Lim, P. O., and Sears, B. B. 1989. 16S rRNA Sequence indicates that plantpathogenic mycoplasmalike organisms are evolutionary distinct from animal mycoplasmas. J. Bacteriol. 171:5901-5906.

26. Musetti, R., Favali, M. A., and Pressacco, L. 2000. Histopathology and polyphenol content in plants infected by phytoplasmas. Cytobios 102:133147.

27. Orenstein, S., Zahavi, T., Nestel, D., Sharon, R., Barkalifa, M., and Weintraub, P. G. 2003. Spatial dispersion patterns of potential leafhopper and planthopper (Homoptera) vectors of phytoplasma in wine vineyards. Ann. Appl. Biol. 142:341-348.

28. Oshima, K., Kakizawa, S., Nishigawa, H., Jung, H. Y., Wei, W., Suzuki, S., Arashida, R., Nakata, D., Miyata, S., Ugaki, M., and Namba, S. 2004. Reductive evolution suggested from the complete genome sequence of a plantpathogenic phytoplasma. Nat. Genet. 36:27-29.

29. Rapussi, M. C. C., Eckstein, B., Flôres, D., Hass, I. C. R., Amorim, L., and Bedendo, I. P. 2012. Cauliflower stunt associated with a phytoplasma of subgroup 16SrIII-J and the spatial pattern of disease. Eur. J. Plant Pathol. 133:829-840.

30. Ronquist, F., and Huelsenbeck, J. P. 2003. MrBayes 3: Bayesian phylogenetic inference under mixed models. Bioinformatics 19:1572-1574.

31. Sambrook, J., and Russel, D. W. 2001. Molecular Cloning: A Laboratory Manual, 3rd ed. Cold Spring Harbor Laboratory Press, Cold Spring Harbor, NY.

32. Seemuller, E., Schneider, B., Maurer, R., Ahrens, U., Daire, X., Kison, H., Lorenz, K. H., Firrao, G., Avinent, L., Sears, B. B., and Stackebrandt, E. 1994. Phylogenetic classification of phytopathogenic mollicutes by sequence analysis of 16s ribosomal DNA. Int. J. Syst. Bacteriol. 44:440-446.

33. Siddique, A. B. M., Guthrie, J. N., Walsh, K. B., White, D. T., and Scott, P. T. 1998. Histopathology and within-plant distribution of the phytoplasma associated with Australian papaya dieback. Plant Dis. 82:1112-1120.

34. Silberschmidt, K., and Campos, A. R. 1944. Estudos relativos à doença superbrotamento ou envassouramento da mandioca. Arq. Inst. Biol. 15:1-12.

35. Souza, L. S., and Fialho, J. F. 2003. A cultura da mandioca. Embrapa mandioca e fruticultura-Sistemas de produção, 8. 1-38. Tech. Bull.

36. Sugio, A., MacLean, A. M., Kingdom, H. N., Grieve, V. M., Manimekalai, R., and Hogenhout, S. A. 2011. Diverse targets of phytoplasma effectors: from plant development to defense against insects. Annu. Rev. Phytopathol. 49:175-195.

37. Tamura, K., Peterson, D., Peterson, N., Stecher, G., Nei, M., and Kumar, S 2011. MEGA5: molecular evolutionary genetics analysis using maximum likelihood, evolutionary distance, and maximum parsimony methods. Mol. Biol. Evol. 28:2731-2739.

38. Tran-Nguyen, L. T. T., Kube, M., Schneider, B., Reinhardt, R., and Gibb, K. S. 2008. Comparative genome analysis of 'Candidatus Phytoplasma australiense' (subgroup tuf-Australia I; rp-A) and ' $\mathrm{Ca}$. Phytoplasma asteris' strains OY-M and AY-WB. J. Bacteriol. 190:3979-3991.

39. Zhao, Y., Wei, W., Lee, I. M., Shao, J., Suo, X., and Davis, R. E. 2009. Construction of an interactive online phytoplasma classification tool, iPhyClassifier, and its application in analysis of the peach X-disease phytoplasma group (16SrIII). Int. J. Syst. Evol. Microbiol. 59:2582-2593. 